\title{
Espiritualidade, Fé e Cura: um olhar sobre a Religiosidade Popular
}

\author{
Adriano Monteiro de Oliveira ${ }^{1}$; Nilton Eliseu Herbes ${ }^{2}$
}

\begin{abstract}
Resumo: A valorização da dimensão espiritual e o estudo da espiritualidade dão significado a algumas interrogações humanas muito ligadas aos valores, a estilos de vida e a crenças do ser humano em Deus. Neste sentido, o presente artigo teve por objetivo descrever e compreender experiências de fé e busca pela cura, por meio da religiosidade popular, tendo como base o estudo de caso dos centros religiosos de Juazeiro do Norte, no Ceará, e São Leopoldo, no Rio Grande do Sul. Ambos possuírem tradição na realização de romarias: para o Padre Cícero ou "Padim Ciço", no caso de Juazeiro; e, para o Padre Réus, no caso de São Leopoldo. Pode-se constatar que a fé dos romeiros é concebida como proteção, confiança, sustentação e alcance de graça. Deste modo, no tocante ao processo de saúde-doença, na assistência do profissional de saúde é necessário que se enxergue nos pacientes, corpo, mente, alma e espírito, promovendo o cuidado integral do ser humano.
\end{abstract}

Palavras-chave: Religiosidade Popular; Fé e cura; Padre Cícero; Padre Reus.

\section{Spirituality, Faith and Healing: A look at the popular religiosity}

\begin{abstract}
The valuation of the spiritual dimension and the spirituality of the study give meaning to some human questions closely linked to values, lifestyles and beliefs of human beings to God. In this sense, this article aims to describe and understand faith experiences and search for a cure, through popular religiosity, based on the case study of the religious centers of Juazeiro do Norte, Ceará and São Leopoldo, in Rio Grande do Sul . Both possess tradition in making pilgrimages: to Father Cicero or "Padim Ciço" in the case of Juazeiro; and to Father Reus in the case of São Leopoldo. It can be seen that the faith of the pilgrims is designed as protection, trust, support and reach for grace. Thus, with respect to the health-disease process in the health care professional is required one to see the patients body, mind, soul and spirit, promoting the comprehensive care of the human being.
\end{abstract}

Keywords: Popular Religiosity; Faith and healing; Father Cicero; Father Reus.

\section{Introdução}

Considerando-se o saber biomédico, centrado na doença, e compreendendo que o indivíduo é um corpo, uma alma, um espírito e o que materializa a integração destes é o sopro, o pneuma ou o Espírito Santo, que tudo move, anima e transcende (HENNEZEL; LELOUP, 2003), é que se verifica a busca de estudos, sobre religiosidade e espiritualidade, relacionados ao processo de cura, construção de crenças e culturas locais em saúde (CAVALCANTE, 2010).

\footnotetext{
${ }^{1}$ Enfermeiro. Especialista em Gerontologia e Saúde Mental. Mestrando em Teologia com habilitação em Dimensões do Cuidado e Práticas Sociais - Faculdades EST. Email: admontoliv@yahoo.com.br;

${ }^{2}$ Doutor em Teologia - Augustana-Hochschule (Alemanha). Docente na Faculdades EST. E-mail: nherbes@yahoo.com.br.
} 
Id on Line Revista Multidisciplinar e de Psicoloqia

Id on Line Multidisciplinary Journal and Psycology

A fé, na doutrina cristã, é fundamentada na crença em um Deus onipotente, que pode e cura as enfermidades. Evidencia-se uma ligação com o sobrenatural, em que há um fio condutor para a busca de soluções relacionadas a sofrimentos, adversidades e enfermidades, servindo de auxílio na recuperação da saúde, seja física ou mental, proporcionando esperança, otimismo e expectativas positivas (PEREIRA, et al., 2007).

A valorização da dimensão espiritual e o estudo da espiritualidade dão significado a algumas interrogações humanas muito ligadas aos valores, a estilos de vida e a crenças do ser humano em Deus. Por essa razão, pressupõe-se que a espiritualidade exerce influência na saúde e na qualidade de vida das pessoas. Diante do exposto, esta pesquisa teve por objetivo descrever e compreender experiências de fé e busca pela cura, por meio da religiosidade popular.

\section{Fé e Cura}

Eu sou o senhor que te cura (BÍBLIA, Êxodos 15,26)

A cura, como dimensão do Plano de Deus para os homens, tem fundamento na Bíblia Sagrada. Nela, encontra-se apoio para crer que Deus deseja curar as doenças. "É ele quem perdoa as tuas faltas e sara as tuas enfermidades" (BÍBLIA, Salmo 103,3). Acredita-se em um "propósito maior de Deus para nossa vida: a salvação" (GAMBARINI, 2000). Neste sentido, a salvação está relacionada a problemas do dia a dia, incluindo-se o sofrimento, a angústia e as enfermidades físicas e mentais. "Vinde a mim, vós todos que estais aflitos sob o fardo, e eu vos aliviarei” (BÍBLIA, Mateus 11, 28). No exercício da fé, “é transferido a Deus o poder de operar a cura e prolongar a vida" (PEREIRA, et al., 2007, p. 51).

$\mathrm{Na}$ promoção à saúde, prevenção e cura de enfermidades, a religiosidade popular pode ser favorável na adoção de comportamentos saudáveis, como por exemplo, a adesão às práticas preventivas e tratamentosas. "Ao contrário da medicina oficial, a cultura dos devotos une a fé à ciência e, dessa maneira, tende a elaborar uma conjunção de saberes e crenças" (PEREIRA, et al., 2007, p. 53). 
Id on Line Revista Multidisciplinar e de Psicoloqia

Id on Line Multidisciplinary Journal and Psycology

Um espaço propício para as expressões da religiosidade popular é a romaria, que nas palavras de Korbes e Woberto é "a viagem que pessoas religiosas fazem a lugares que consideram sagrados, para ali rezar, cumprir promessas e agradecer graças recebidas. Tais lugares estão geralmente marcados por templos e santuários, túmulos de santos e de pessoas veneradas" E o romeiro ou peregrino é sempre "alguém que pede ou a cura do corpo ou a conversão do coração" (KORBES; WOBERTO, 2013).

Cavalcante encontrou as concepções de cura para os romeiros: cura como sinônimo de saúde; cura atribuída a uma divindade; a cura como recompensa, milagre; e, a cura social. A autora apresentou, ainda, o círculo da cura pela fé, a partir da religiosidade popular:

Diálogo com a fé - representa um diálogo interno referenciado geralmente pelo sofrimento, pelos sintomas em torno de um agravo ou doença. [...] É no contexto do sofrimento da doença que a fé se manifesta como elemento potencializador de esperança em busca de uma graça. Assim se inicia um diálogo com as crenças internas e a fé na negociação com a divindade representativa para o alcance de cura através de uma promessa, um pedido ou alcance de graça;

Expressão da fé - representa a materialização da fé expressa em performance de símbolos, ritos, oferendas, sacrifícios, oferendas de ex-votos como pagamento, agradecimento pela graça alcançada;

Renovação da fé - corresponde aos momentos de renovação, fortalecimento da fé, superando a dúvida da crença inicial [...]. A renovação da fé também se encontra na expressão dos rituais, publicizando-os através dos votos, de novas promessas e o retorno ao cenário sagrado e de cura para performance dos rituais (CAVALCANTE, 2010, p. 74).

Os romeiros ou peregrinos constroem um mundo mítico, a partir de suas crenças e rituais acerca do adoecimento e da cura, atrelado à religiosidade popular. Conforme se observa, nas devoções, a busca pela cura representa a construção da fé, em uma trajetória cíclica, que envolve a experiência do adoecer, o sofrimento e o pedido de graça (diálogo com a fé); a expressão de rituais e símbolos (a expressão da fé); e a renovação dos ritos, ressignificando a vida em seus aspectos emocionais, físicos e espirituais (renovação da fé).

\section{Procedimentos Metodológicos}

Para desenvolvimento desta pesquisa, inicialmente, foi realizada uma revisão de literatura em livros, teses, dissertações, artigos e sites na internet, contendo informações e relatos de religiosidade popular no Brasil, tomando como base as cidades de Juazeiro do 
Id on Line Revista Multidisciplinar e de Psicoloqia

Id on Line Multidisciplinary Journal and Psycology

Norte, no Estado do Ceará, Região Nordeste, e São Leopoldo, no Estado do Rio Grande do Sul, na região Sul do país. Estas cidades foram escolhidas por possuírem tradição na realização de romarias para o Padre Cícero ou "Padim Ciço", no caso de Juazeiro do Norte, e para o Padre Réus, no caso de São Leopoldo.

Além do estudo bibliográfico, foram realizadas visitas de campo às referidas cidades e observação participante (CORREIA, 2009) durante as romarias locais. No caso de Juazeiro do Norte, optou-se por acompanhar a Romaria de Nossa Senhora das Candeias, ocorrida no mês de fevereiro. As romarias em Juazeiro foram motivadas por Padre Cícero, que hoje recebe a devoção de 2,5 milhões de romeiros (PMJN, 2016). Em São Leopoldo, realiza-se, no segundo domingo do mês de julho, a Romaria do Padre Réus, que anualmente registra 1,5 milhão de pessoas visitando o Santuário Sagrado Coração de Jesus (BERRINELLI, 2016).

\section{Resultados e Discussão}

Nos tópicos seguintes, serão descritas experiências que colocam a religiosidade popular como um referencial em torno de saberes e práticas na busca pela cura por meio da fé. Serão apresentados os casos de romeiros de Juazeiro do Norte, CE, e São Leopoldo, RS.

\subsection{Os romeiros do "Padim Ciço"}

Bendito e louvado seja, a luz que mais alumeia, valei-me meu padrinho Ciço e a Mãe de Deus das Candeia (Trecho da canção "Romaria a Joazeiro”, Clemilda).

A cidade de Juazeiro do Norte, ou simplesmente Juazeiro, como é comumente chamada por seus munícipes, é um centro religioso de peregrinação, localizado no interior do Estado do Ceará, na microrregião Cariri, na região nordeste do Brasil. O município possui uma área de 248,83 km² e densidade demográfica de 1.004,45 hab./km². Segundo o Censo Demográfico do IBGE de 2010, Juazeiro possui uma população de 249.939. Para 2015, a população foi estimada em 266.022 habitantes (IPECE, 2016).

Uma cidade populosa com nome de árvore se tornou então um reduto armado em sua própria defesa e, ao mesmo tempo, a capital da fé de romeiros, beatos, artesãos e comerciantes, entre os crentes da salvação neste e no outro mundo. Hoje está entre 
Id on Line Revista Multidisciplinar e de Psicoloqia

Id on Line Multidisciplinary Journal and Psycology

as cidades mais ricas do Ceará, recebendo mais de dois milhões de peregrinos e turistas a cada ano (ARAGÃO, 2014).

As romarias de Juazeiro ocorrem desde a última década do século XIX e foram motivadas por um milagre envolvendo o Padre Cícero, nascido na cidade de Crato, CE, vigário à época em "Joazeiro", e a beata Maria de Araújo, em 1 de março de 1889:

Naquela data, ao participar de uma comunhão geral, oficiada por ele, na capela de Nossa Senhora das Dores, a beata Maria de Araújo ao receber a hóstia consagrada, não pôde degluti-la pois a mesma transformara-se em sangue. $\mathrm{O}$ fato repetiu-se outras vezes, e o povo achou que se tratava de um novo derramamento do sangue de Jesus Cristo e, portanto, um milagre autêntico. As toalhas com as quais se limpava a boca da beata ficaram manchadas de sangue e passaram a ser alvo da veneração de todos (MARQUES, 1999).

Em razão deste acontecimento e sua repercussão, Padre Cícero foi alvo de investigações por parte da Igreja, que culminou em sua suspensão de ordem. Foram sanções impostas ao Padre Cícero:

\begin{abstract}
Benzer objetos de piedade; abençoar pessoas; Receber romeiros e visitas; Falar com pessoas de casa sobre milagres; Pregar, confessar e administrar sacramento; Confessar-se; receber presentes; celebrar; Construir uma igreja (do Sagrado Coração de Jesus) embora se tratasse do cumprimento de promessa por graça alcançada; Desdizer-se de púlpito; Denunciar mais de uma vez os fatos extraordinários; Combater a "ideia supersticiosa de santidade ditas pelos romeiros"; Pôr fím às romarias ou sair da diocese (portanto do Ceará); Declarar para o povo que quem cresse nos fatos condenados ficaria privado dos sacramentos até em artigo de morte; Declarar para o povo que não podia se comunicar com os romeiros e não queria comunicar-se com os seguidores ou com os romeiros visitantes; Restituir todo o dinheiro recebido do povo; Mandar recolher os livros e opúsculos escritos em defesa daquele evento (GUERRA, 2015).
\end{abstract}

Após a suspensão, Padre Cícero se instalou em sua residência particular e os devotos esperavam que ele abrisse sua janela para abençoá-los. Como não podia mais celebrar batismos, passou a apadrinhar crianças da própria cidade e também os filhos dos romeiros, tornando-se conhecido como padrinho Padre Cícero ou Padim Ciço. "Tornou-se de fato, um 'santo' e profeta infalível, alguns o tinham até como pessoa da Santíssima Trindade" (GUERRA, 2015, p. 57).

As romarias se intensificaram com a morte do Padre, em 1934, aos 90 anos de idade. "Feitas, sobretudo, a pé (levavam muitos dias e exigiam sacrifício). Com o processo de popularização do uso do caminhão [...] o 'pau-de-arara' tornou-se por excelência o meio de 
Id on Line Revista Multidisciplinar e de Psicoloqia

Id on Line Multidisciplinary Journal and Psycology

transporte dos romeiros" (BRAGA, 2010, p. 150). Na atualidade, houve a substituição dos caminhões por ônibus (FIGURA 1).

Figura 1 - Ônibus de romeiros

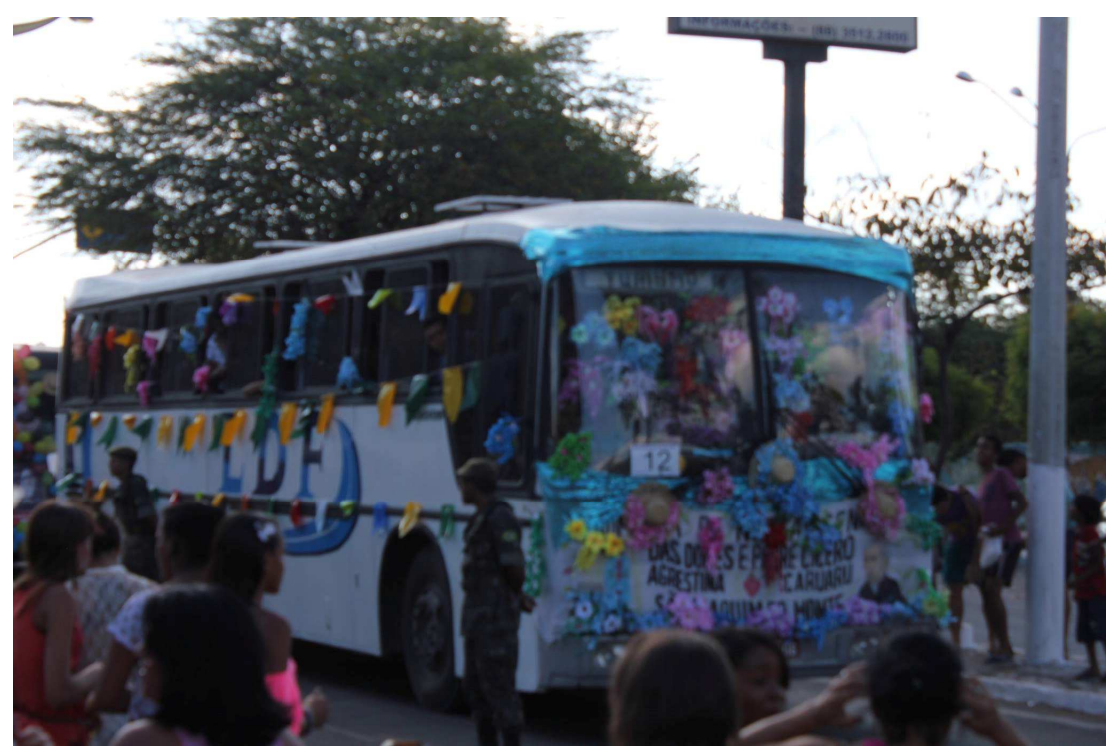

Os romeiros enfeitam seus transportes com fitas coloridas, chapéus de palha e faixas com frases religiosas e, geralmente, com a identificação de sua localidade de origem. Quando chegam à cidade, são recebidos com grande alegria pelos populares na "Terra de Padre Cícero". A figura do Padre está enraizada na maioria das famílias, nas gerações passadas e também presentes, ligadas a uma forma de crer (NASCIMENTO JUNIOR, 2011, p. 90).

Em dezembro de 2015, o Vaticano anunciou a reconciliação de Padre Cícero com a Igreja. Deste modo, não há mais fatores impeditivos para que o Padre seja beatificado ou canonizado. A reconciliação ficou conhecida como "Dia do Perdão" (FIGURA 2). Pela primeira vez, em 30 de janeiro de 2016, uma imagem de padre Cícero adentrou um templo católico, com a devida permissão da Igreja, durante a realização da romaria das Candeias, que atraiu cerca de 300 mil romeiros à cidade. 
Figura 2 - Dia do Perdão

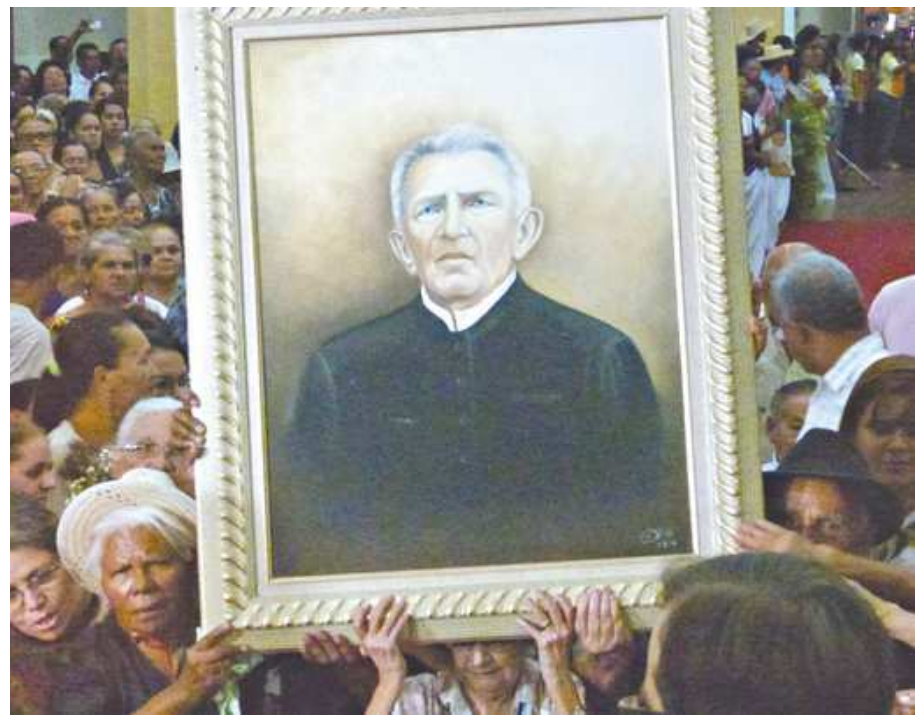

Fonte: SANTOS, 2016.

A expressão da religiosidade popular em Juazeiro do Norte representa uma espiritualidade historicamente construída, "mantida e sustentada na verdade de cada romeiro quando narra sua história, fala, ora, caminha, se alegra, celebra, expressando por inteiro o que sempre representou a inteireza do ser que é" (CAVALCANTE, 2010, p. 60).

Oficialmente, são reconhecidas oito romarias ocorridas ao longo do ano em Juazeiro do Norte (GUERRA, 2015): Santos Reis (06 de janeiro); São Sebastião (20 de janeiro); Nossa Senhora das Candeias (02 de fevereiro), representada na Figura 3; nascimento de Padre Cícero (24 de março); falecimento de Padre Cícero (20 de julho); Nossa Senhora das Dores (15 de setembro); São Francisco (04 de outubro); e, Dia de Finados (02 de novembro). Destas, destacam-se as ocorridas em fevereiro, setembro e novembro, que detêm um maior número de visitantes.

A promessa e a cura fazem parte da cultura do romeiro. Assim, durante as festividades e com o propósito de agradecer as graças e curas alcançadas, os visitantes percorrem os locais nos quais o Padre Cícero passava a maior parte do seu tempo (PEREIRA, et al., 2007). 
Id on Line Hevista Multidisciplinar e de Psicoloqia

Id on Line Multidisciplinary Journal and Psycology

Figura 3 - Romaria de Nossa Senhora das Candeias

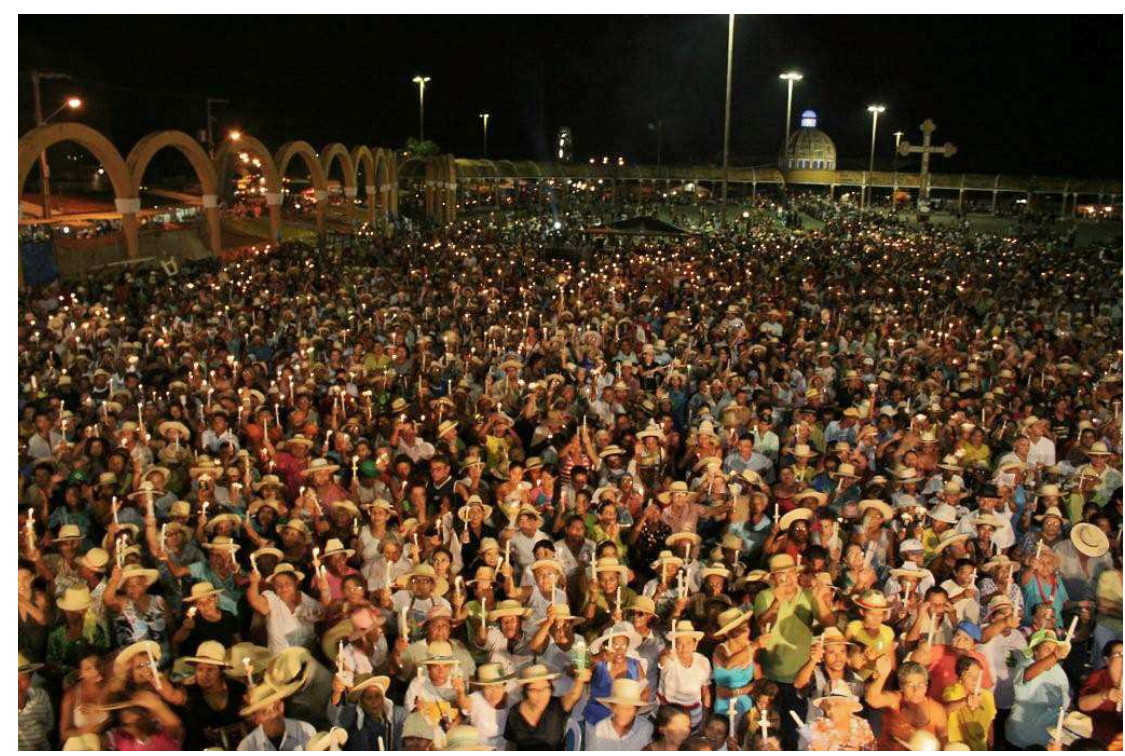

Fonte: PMJN, 2016.

Dentre os locais mais visitados, destacam-se: a estátua do Padre Cícero (FIGURA 4), uma imagem com 27 metros de altura, localizada na colina do Horto; o Museu Vivo; a Basílica de Nossa Senhora das Dores; a Capela do Perpétuo Socorro, onde está localizado o túmulo de Padre; o santuário do Coração de Jesus; e, o Santuário de São Francisco.

Figura 4 - Estátua do Padre Cícero

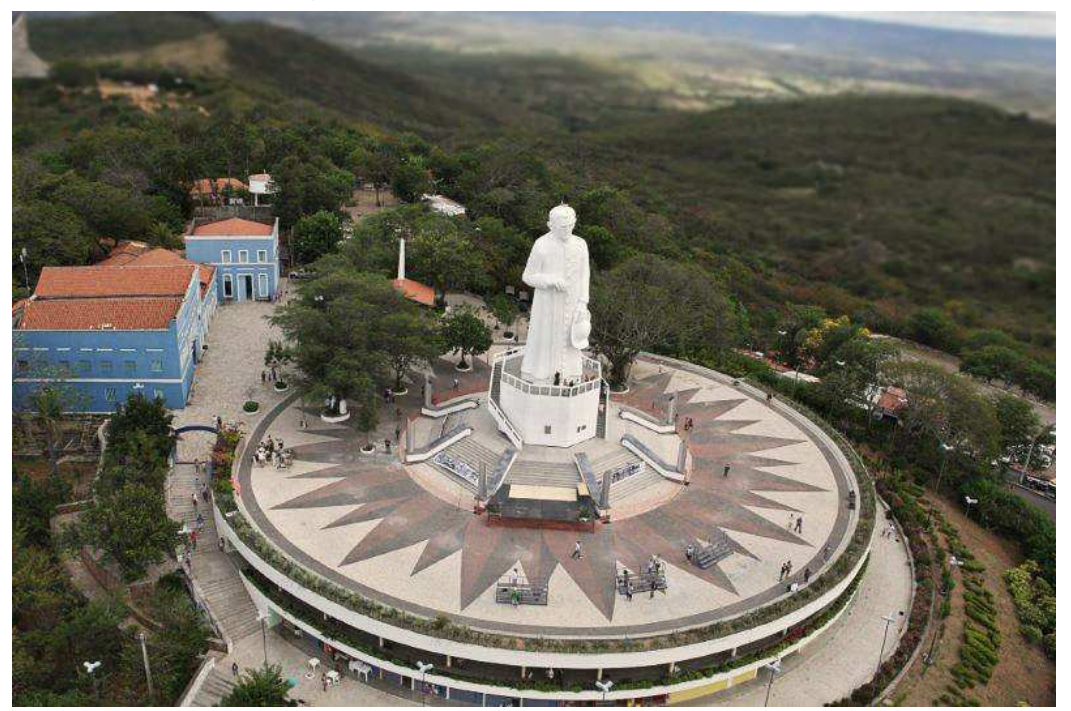

Fonte: Diário do Sertão, 2016. 
Id on Line Revista Multidisciplinar e de Psicoloqia

Id on Line Multidisciplinary Journal and Psycology

Os romeiros do Padim Ciço expressam uma fé sustentada na crença de que ele atua como um intermediário divino. Pereira et al. (2007, p. 51). apresentam relatos, a partir de diálogos com os devotos do Padre: "eu fiz a promessa com meu Padim Ciço e minha mãe das Dores e graças a Deus, eu alcancei a graça"; "aí eu fiz uma promessa e graças a Deus e meu Padim Ciço eu fui valida”. Em muitos dos casos, há histórias de promessas e curas, como a relatada a seguir:

Eu fiz a promessa para ficar recuperado da dor do estômago, recuperei e terminei ficando bom. Hoje não sinto mais nada, faz dois anos que aconteceu isso, e quase que morro! Eu paguei essa promessa, pra tirar uma foto na estátua e entregar aqui na casa do Padim Ciço. Faz uns 12 anos que venho, e toda vida que venho pago promessa (PEREIRA, et al., 2007, p. 46).

Os romeiros acreditam que a cura se dá por uma atitude de fé, que, diante de uma situação difícil, transforma-se em uma possibilidade de recuperar a saúde. Trata-se da cura simbólica, definida por Cavalcante como "permeada por crenças, atrelada a valores humanos e culturais, baseada em rituais, mitos e símbolos de uma determinada cultura" (CAVALCANTE, 2010, p.62).

A autora complementa que "nas curas sagradas ou religiosas, o cenário envolve uma igreja, templos, túmulo ou um lugar sagrado de peregrinação" (CAVALCANTE, 2010, p.64). A cura é percebida como uma recompensa ou milagre, que "representa uma visão de troca simbólica em que o romeiro que faz uma promessa ao Padre Cícero tem o retorno e paga com rituais de oferendas, como com ex-votos" (CAVALCANTE, 2010, p. 67). O termo "ex-voto", abreviação latina de ex-voto suscepto, "o voto realizado", designa pinturas, estatuetas e variados objetos doados como forma de agradecimento por uma graça alcançada (ENCICLOPÉDIA, 2016).

Em Juazeiro do Norte os ex-votos são depositados no Museu Vivo de Padre Cícero, na Casa dos Milagres e na Cruz do Cruzeiro. São partes do corpo humano, cabeças, membros e órgãos em miniatura esculpidos em madeira, gesso, barro, cera. São depositados tufos de cabelo, muletas, cadeiras de roda, caixas de remédio, vestimentas, cartas, quadros, fotografias, cruzes, todos esses objetos carregados de sentimentos como felicidade e dor pela libertação do mal representado (GUERRA, 2015, p. 80). 
Id on Line Revista Multidisciplinar e de Psicoloqia

Id on Line Multidisciplinary Journal and Psycology

A Figura 5 representa uma pequena mostra do que é possível encontrar em termos de quantidade e variedade de ex-votos na "Casa dos Milagres", em Juazeiro. São vestidos de noiva, fotografias, diplomas, esculturas em madeira, dentre outros.

Figura 5 - Ex-votos de Juazeiro

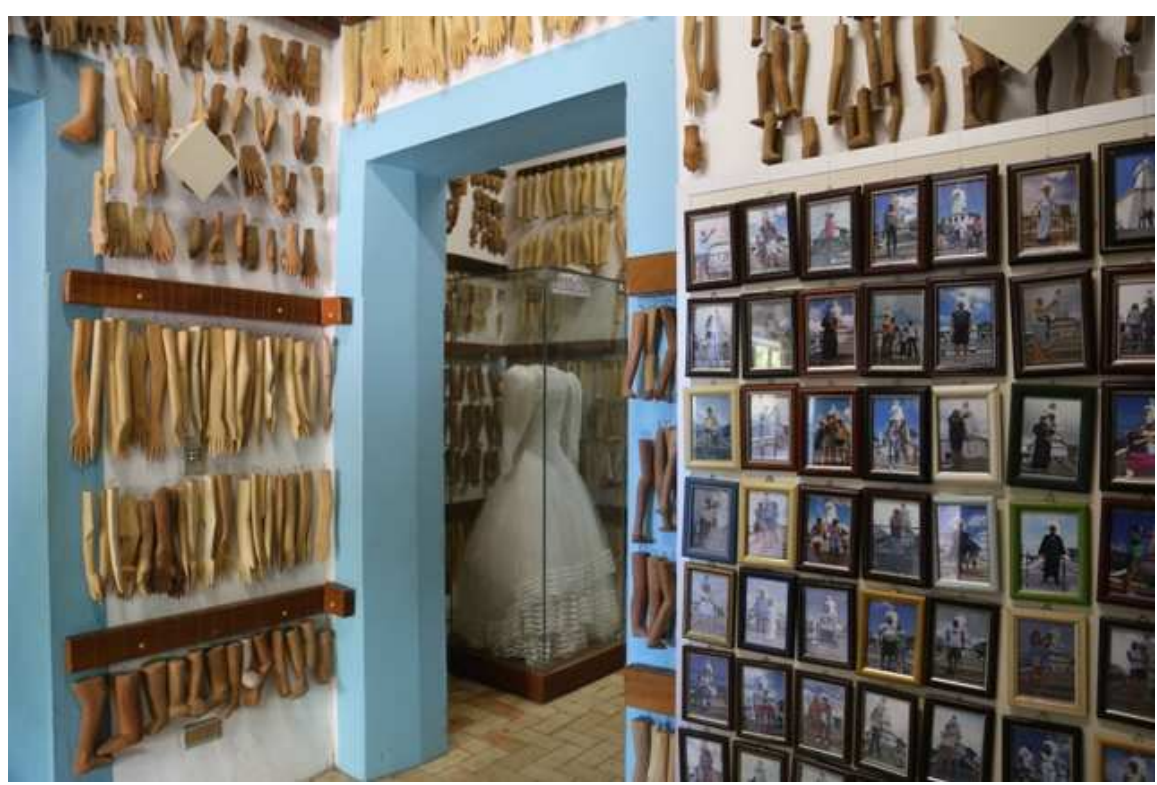

Fonte: SOUZA, 2016.

As romarias, na atualidade, deixaram de ser sobretudo uma experiência de peregrinação com caráter apenas religioso e se tornaram também uma experiência de lazer. Contudo, dentre os romeiros mais idosos, a experiência religiosa continua sendo a parte importante do viver e da construção do sentido da vida. Percebe-se que para as gerações mais velhas, nas romarias:

\begin{abstract}
se inseriam e se inserem a metáfora do sofrimento e do sacrifício; para as mais novas, essas dimensões são sobrepujadas pela lógica do lazer, do deslocar-se em busca de experiências que - dando-se fora de suas vidas ordinárias - possibilitam uma relação mais prazerosa com a vida. Um prazer que se dará mais nas relações intra-humanas, do que na relação com o santo, o universo religioso (BRAGA, 2010, p. 160).
\end{abstract}

Não obstante, notoriamente, no caso dos romeiros do Padim Ciço, a cura envolve um processo simbólico e se insere em um contexto cultural, representado nos rituais, doações de ex-votos e fé no processo saúde-doença. 
Id on Line Revista Multidisciplinar e de Psicoloqia

Id on Line Multidisciplinary Journal and Psycology

\section{Peregrinos do Padre Réus}

O Padre João Batista Reus nasceu na Alemanha, em 1868. Veio ao Brasil, mais precisamente para o Rio Grande do Sul, no ano de 1900. Faleceu em 1947, sendo sepultado no cemitério de São Leopoldo. Desde então, o Padre adquiriu de seus devotos uma permanente demonstração de fé e confiança, intitulando-o de "Milagroso Padre Reus". Em 1953, foi iniciado seu Processo de Beatificação. A pedido dos devotos do Padre, em 1958, iniciou-se a construção do Santuário do Sagrado Coração de Jesus (FIGURAS 6 e 7), que foi inaugurado em 1970 (KORBES; WOBERTO, 2013).

Figuras 6 e 7 - Santuário do S. Coração de Jesus
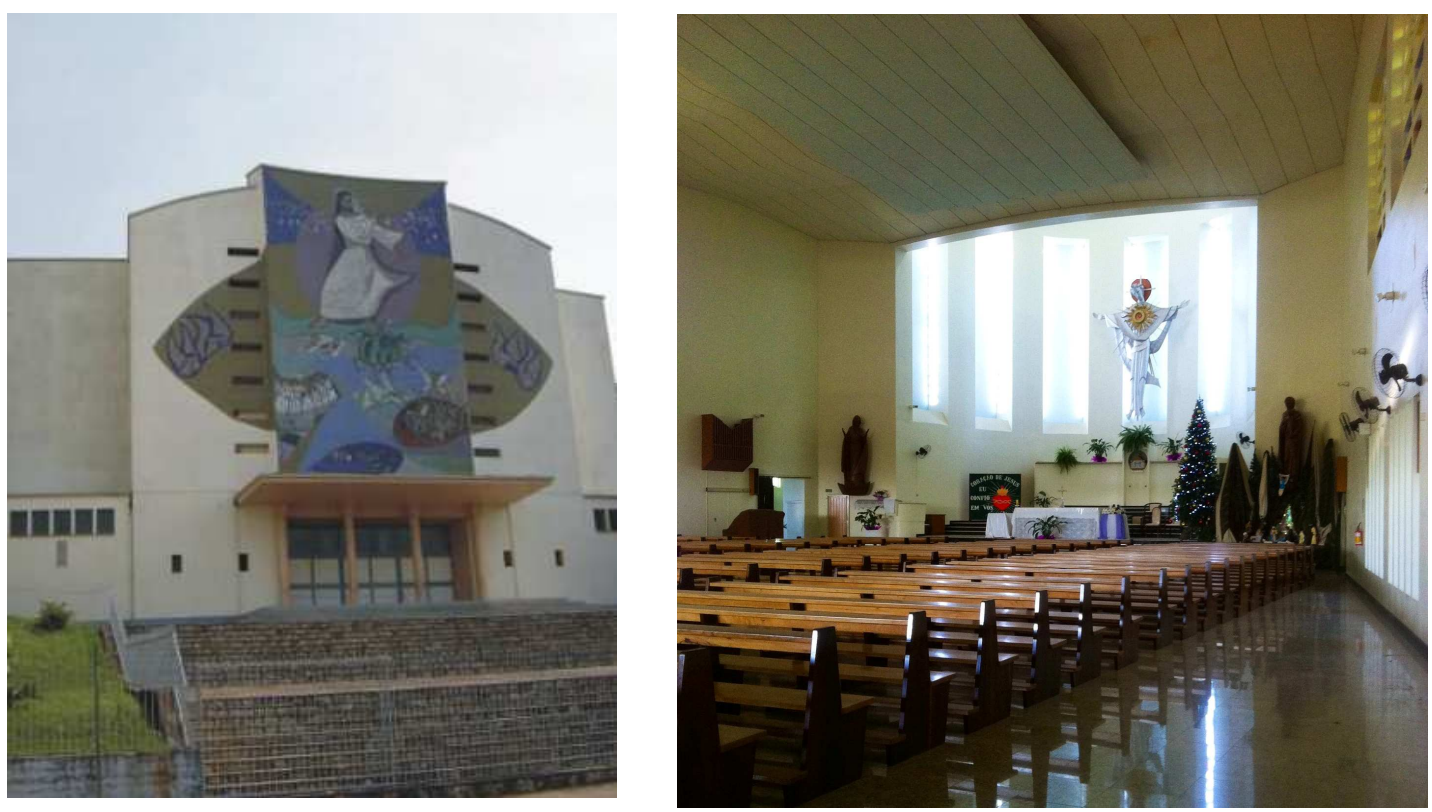

Fonte: arquivo pessoal

O Santuário, por força de Lei Municipal, nº 8445 (PREFEITURA, 2016), de 10 de maio de 2016, está salvaguardado como patrimônio cultural e imaterial. Nele, encontra-se o túmulo do Padre Reus, que recebe milhares de devotos a cada ano. "Elevam preces, agradecem graças alcançadas, entoam cantos e cumprem promessas" (KORBES; WOBERTO, 2013, p. 2).

Dentre os ritos, experiências religiosas, expressões de fé e devoção dos romeiros do Padre Reus, estão: 
Id on Line Hevista Multidisciplinar e de Psicologia

Id on Line Multidisciplinary Journal and Psycology

1. Participação na romaria, "A caminhada do peregrino do Padre Reus" (KORBES; WOBERTO, 2013, p. 10), que consiste em uma caminhada desde a Igreja Matriz de São Leopoldo até o Santuário S. Coração de Jesus (FIGURA 8). Salienta-se que no ano de 2016, realizou-se a décima romaria do Padre Reus, no dia 10 de julho.

Figura 8 - Romaria de Padre Reus

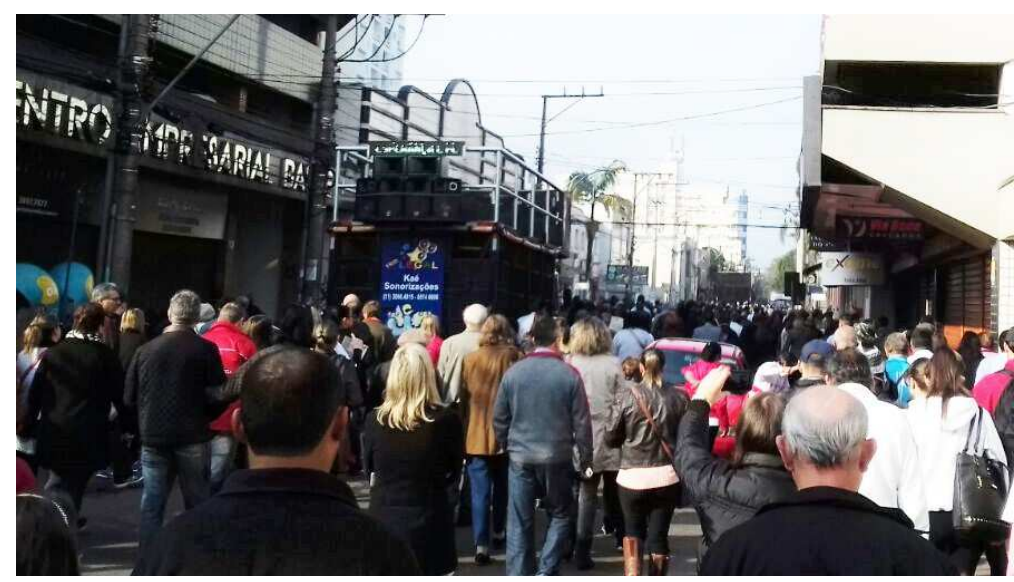

Fonte: arquivo pessoal

1. Visita ao Santuário para acender velas e ajoelhar-se ao túmulo do Padre, ofertando-lhe flores. De acordo com a cultura do romeiro, deve-se passar a flor na cruz com a foto do padre Reus, junto ao túmulo (FIGURA 9).

Figura 9 - Romeiros junto ao túmulo

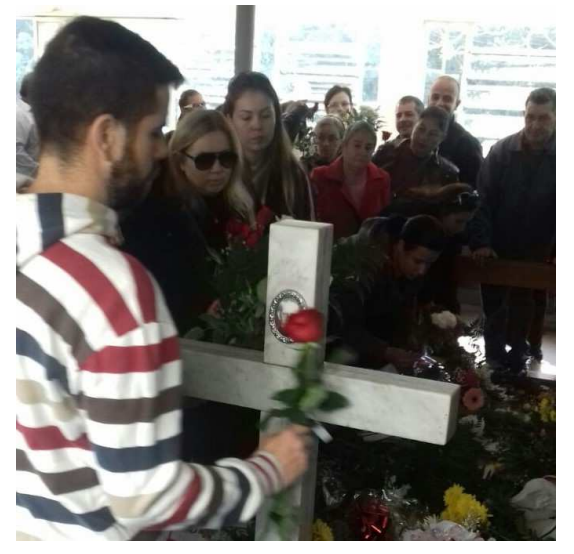

Fonte: arquivo pessoal 
Id on Line Revista Multidisciplinar e de Psicoloqia

Id on Line Multidisciplinary Journal and Psycology

¿ Em seguida, o romeiro desce para a cripta, um local de oração e reflexão, assiste missa e, opcionalmente, faz sua "reconciliação pelo Sacramento da Confissão" (KORBES; WOBERTO, 2013, p. 11).

¿ Por fim, há a oferta de ex-votos, comumente representados por bancos de madeira (FIGURA 10), imagens, fotos em porta-retratos e pequenas placas em mármore, com a expressão “Graça alcançada” (FIGURA 11).

Figuras 10 e 11 - Ex-votos para o Padre Reus
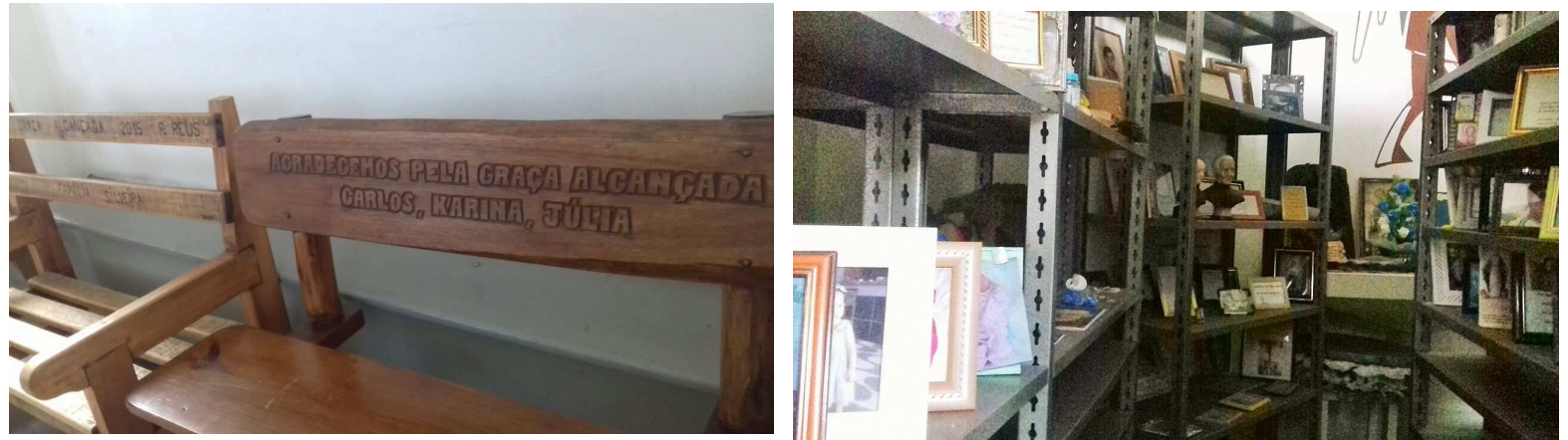

Fonte: arquivo pessoal

Ao longo do ano, são recebidas diversas cartas relatando graças e favores obtidos por intercessão do Padre Reus. Muitas delas especialmente relacionam-se com a "Novena ao Padre Reus" (KORBES; WOBERTO, 2013, p. 5):

Ó Deus, que vossa infinita bondade e misericórdia inspirastes ao Vosso humilde servo João Baptista tão ardente desejo de perfeição e o comulastes de tantas e tão extraordinárias mercês, concedei-me a graça de imitá-lo na entrega total ao Sagrado Coração de Jesus, no amor à cruz e ao sacrifício, na estima da Santa Missa, na Intimidade com Jesus Sacramentado, no zelo pelas vocações sacerdotais e na devoção filial ao Imaculado Coração de Maria, Medianeira de todas as graças. Ó Deus, que glorificais a quem vos glorificai o Vosso servo João Baptista, que em vida Vos amou e glorificou, concedendo-me, por sua intercessão a graça (....) que instantemente Vos peço. Por Jesus Cristo, Nosso Senhor. Amém.

Percebe-se, neste caso, a cura atribuída a uma divindade, que conforme relatado por Cavalcante, consiste em "uma crença mágico-religiosa que transfere ou atribui a alguém ou a uma divindade, santo ou curandeiro o poder de curar" (CAVALCANTE, 2010, p. 67). 
Id on Line Revista Multidisciplinar e de Psicoloqia

Id on Line Multidisciplinary Journal and Psycology

\section{Considerações Finais}

Observando-se o fenômeno da busca pela cura, por meio da fé, tendo como base os casos dos centros religiosos de Juazeiro do Norte e São Leopoldo, pode-se constatar que a fé dos romeiros é concebida como proteção, confiança, sustentação e alcance de graça. A cura é associada ao sofrimento, alívio de algum mal, e atrela-se em um saber construído na religiosidade popular. Deus promete restaurar seu povo com um tempo de cura, segundo Jeremias: "Vou pensar-lhes as feridas e curá-las, e lhes proporcionar abundância de felicidade e segurança" (BÍBLIA, Jeremias 33, 6).

Observa-se que a espiritualidade e a religiosidade dos romeiros são motivadoras, expressas como atos de devoção ou pagamento de promessa das bênçãos obtidas, que geralmente estão relacionadas à família, à prosperidade e à saúde. Assim, por meio de oferenda, como no caso dos ex-votos, ou em sacrifício, envolvendo o caminhar longas distâncias, muitas vezes a pé, subir escadas de joelhos, enfim, colocar-se no limite da resistência humana, o romeiro se representa como um elemento de entrega e cura.

Deste modo, no tocante ao processo de saúde-doença, na assistência do profissional da saúde é necessário que se enxergue nos pacientes, corpo, mente, alma e espírito, superando a abordagem fragmentada do saber biomédico e promovendo o cuidado integral ao ser humano.

\section{Referências}

ARAGÃO, G. S. A sombra do Padre Cícero...Paralellus, Recife, v. 5, n. 10, p. 343-360, jul./dez. 2014. Disponível

em: <http://www.unicap.br/ojs/index.php/paralellus/article/view/490> Acesso em: 05 Jul. 2016, p, 354.

BRAGA, A. M. C. Devoção, lazer e turismo nas romarias de Juazeiro do Norte, CE: reconfigurações romeiras dos significados das romarias a partir de tensões entre as categorias turismo e devoção. PLURA, Revista de Estudos de Religião, vol.1, no 1, 2010, p. 149-161. Disponível em: <http://www.abhr.org.br/plura/ojs/index.php/plura/article/viewFile/12/14> Acesso em 09 Jul. 2016.

BERRINELli, S. 10 ${ }^{a}$ Romaria do Padre Reus acontece no dia 10 de julho em São Leopoldo. 
Id on Line Revista Multidisciplinar e de Psicoloqia

Id on Line Multidisciplinary Journal and Psycology

<http://www.jornalnh.com.br/_conteudo/2016/04/noticias/regiao/308487-10-romaria-dopadre-reus-acontece-no-dia-10-de-julho-em-sao-leopoldo.html> Acesso em 10 Jul. 2016

BÍBLIA. Bíblia sagrada Ave Maria. 203 ed. São Paulo: Ave Maria, 2014.

CAVALCANTE, A. H. Experiências formadoras dos romeiros "do Padim Ciço": Entre a busca de cura, rezas e ritos. Doutorado em Educação [Tese]. Programa de Pós-graduação em Educação Brasileira. Universidade Federal do Ceará - UFC: Fortaleza, 2010. 137 p. Disponível em: <www.repositorio.ufc.br/bitstream/riufc/3377/1/2010_Tese_AHCavalcante.pdf> Acesso em 26 Jun. 2016.

CORREIA, M. C. B. A observação participante enquanto técnica de investigação. Pensar $\begin{array}{lllllll}\text { Enfermagem, } & \text { v. } & 13, & \text { n. } & 2009 . & \text { Disponível em: }\end{array}$ <http://pensarenfermagem.esel.pt/files/2009_13_2_30-36.pdf> Acesso em: 16 Jan. 2016.

DIÁRIO DO SERTÃO. Estátua de Padre Cícero no Horto, em Juazeiro - CE. Disponível em: <http://www.diariodosertao.com.br/noticias/religiao/108543/aos-pes-da-estatua-fieis-epadre-de-cajazeiras-comentam-perdao-do-vaticano-ao-padre-cicero.html> Acesso em 25 Abr. 2016.

ENCICLOPÉDIA Itaú Cultural. Ex-votos. Disponível em: <http://enciclopedia.itaucultural.org.br/termo5433/ex-voto> Acesso em 09 Jul. 2016.

GAMBARINI, A. L. Cura das Enfermidades: Benefício de Jesus. 23 ed. São Paulo: Ágape, 2000.

GUERRA, L. B. G. Juazeiro Do Norte: Religiosidade e Desenvolvimento. Dissertação (Mestrado em Ciência das Religiões). Universidade Lusófona de Humanidades e Tecnologias. $2015 . \quad 101 \quad$ p. Disponível em: <http://recil.grupolusofona.pt/bitstream/handle/10437/6772/Dissertacao_Lucia_Bezerra.pdf?s equence=1> Acesso em: 09 Jul. 2016, p. 55.

HENNEZEL. M; LELOUP, J. Y. A arte de morrer. Petrópolis: Vozes, 2003.

IBEGE - Instituto Brasileiro de Geografia e Estatística. Censo Demográfico 2010. Disponível em: <http://www.ibge.gov.br/home/estatistica/populacao/censo2010/> Acesso em: 25 jan. 2016.

IPECE. Perfil Básico do Município de Juazeiro do Norte. 2015. Disponível em: <http://www.ipece.ce.gov.br/publicacoes/perfil_basico/pbm-2015/Juazeiro_do_Norte.pdf> Acesso em: 14 jan. 2016.

KORBES, A.; WOBERTO, A. Guia do Peregrino. 5 ed. Livraria e Editora Padre Reus: Porto Alegre, 2013. 
Id on Line Revista Multidisciplinar e de Psicoloqia

Id on Line Multidisciplinary Journal and Psycology

MARQUES, Daniel Walker Almeida. Pequena Biografia de Padre Cícero. Juazeiro do Norte: eBookLibris, 1999.

NASCIMENTO JUNIOR, J. I. "Rogai por nós": Religião, Morte e Antropologia. Dissertação (Mestrado em Antropologia), Universidade Federal de Pernambuco. Recife, 2011. Disponível <www.tesesedissertacoes.com.br/ppgaufpe/dissertacoes/2011/JI_dissertacao_2011.pdf em: Acesso em: 08 Jul. 2016.

PEREIRA, C. M. C.; SÁ, L. D.; MUNIZ, C. C.; DIAS, M. D. Promessas e curas: relatos de devotos do Padre Cícero à luz da história oral de vida. Religare (UFPB), v. 1, n.2, p. 43-56, 2007. Disponível em: <http://periodicos.ufpb.br/index.php/religare/issue/view/1263> Acesso em: 05 Jul. 2016.

PMJN - Prefeitura Municipal de Juazeiro do Norte. Romarias. Disponível em: <http://www.juazeiro.ce.gov.br/Cidade/Romarias/> Acesso em 10 Jul. 2016.

PREFEITURA Municipal de São Leopoldo. Lei $\mathbf{n}^{\mathbf{0}}$ 8445. Disponível em: $<$ https://leismunicipais.com.br/a1/rs/s/sao-leopoldo/lei-ordinaria/2016/845/8445/lei-ordinarian-8445-2016-reconhece-o-santuario-sagrado-coracao-de-jesus-como-lugar-de-ritos-ecelebracoes-para-fins-de-salvaguarda-do-patrimonio-cultural-e-imaterial-bem-institui-edeclara-como-area-especial-de-interesse-cultural-aeic-o-perimetro-do-santuario-sagradocoracao-de-jesus-e-da-outras-providencias> Acesso em 10 Jul. 2016.

SANTOS, E. Imagem de Padre Cícero retorna e marca festejos. Disponível em: $<$ http://diariodonordeste.verdesmares.com.br/cadernos/regional/imagem-de-padre-ciceroretorna-e-marca-festejos-1.1484016> Acesso em 26 Abr. 2016.

SOUSA, R. Acervo digital da Professora Ruth Sousa: Projeto Ex-votos do Brasil. Disponível em: <https://projetoex-votosdobrasil.net/santuarios-ne> Acesso em 10 Jul. 2016.

Como citar este artigo (Formato ABNT):

OLIVEIRA, A.M.; HERBES, N.E. Espiritualidade, fé e cura: um olhar sobre a religiosidade popular. Id on Line Revista Multidisciplinar e de Psicologia, Set-Out de 2016, vol.10, n.31, Supl 2, p. 147-162. ISSN 19811179.

Recebido: 15/09/2016

Aceito: 23/09/2016 